\title{
Mobil Hava Baz İstasyonu için En İyi Konumun Bulunmasında Optimizasyon Algoritmalarının Karşılaştırılması
}

\section{Comparison of Optimization Algorithms on Finding Optimum Location for Mobile Aerial Base Station}

\author{
Serhat Celil İLERI \\ Ondokuz Mayıs Üniversitesi \\ Bilgisayar Mühendisliği Bölümü \\ celil.ileri@bil.omu.edu.tr \\ ORCID: 0000-0002-0259-0791
}

\author{
Selçuk ASLAN \\ Erciyes Üniversitesi \\ Uçak Mühendisliği Bölümü \\ selcukaslan@erciyes.edu.tr \\ ORCID: 0000-0002-9145-239X
}

\author{
Sercan DEMIRCi \\ Ondokuz Mayıs Üniversitesi \\ Bilgisayar Mühendisliği Bölümü \\ sercan.demirci@omu.edu.tr \\ ORCID: 0000-0001-6739-7653
}

\section{Öz}

Insansız hava araçları (IHA), artan uçuş süreleri, iyileștirilmis komuta-kontrol sistemleri ve tașıma kapasiteleri sayesinde geçtiğimiz yillarda askeri ve ticari pek çok projede başarı ile kullanılmıştır. Ancak bahsedilen araçların hizmet süre ve kalitesi genellikle daha önce belirlenen ya da anlik olarak bulunan konumlarına doğrudan bağlıdır. Bu çalışmada baz. istasyon özellikli bir insansiz hava aracinin kullanicllara hizmet vermesi amacl ile uygun lokasyonu Harmoni Arama (Harmony Search, HS) ve Havai Fişek (Fireworks, FW) algoritmalarindan faydalanılarak bulunmaya çalışılmıştır. Elde edilen sonuçlar Parçacık Sürü Optimizasyon (Particle Swarm Optimization, PSO) ve Yapay Arl Koloni (Artificial Bee Colony, ABC) algoritmalar tarafindan bulunan sonuçlar ile karşılaştırılmıștır. Karşılaştırma sonuçları HS algoritması ile belirlenen konumlarda mobil baz istasyonunun PSO, ABC ve $F W$ algoritmalart ile belirlenen konumlara kıyasla daha başarılı hizmet verebileceğini göstermiştir.

Anahtar Sözcükler: Insansız Hava Araçları, Konumlandırma, Harmoni Arama Algoritması, Havai Fişek Algoritması

Gönderme ve kabul tarihi: 03.03.2021 - 11.05.2021

Makale türü: Araştırma

\section{Abstract}

In recent years, unmanned aerial vehicles (UAVs) with the increasing flying times, improving commandcontrol systems, and carrying capacities have been used successfully for various military and commercial projects. However, the time and qualities of the services provided by the mentioned vehicles are directly related to the locations determined previously or found instantly. In this study, an appropriate location of a UAV equipped with the base station capability for serving to the users is tried to be determined by utilizing the Harmony Search (HS) and Fireworks $(F W)$ algorithms. The obtained results are also compared with the results obtained by the PSO and $A B C$ algorithms. Comparative results show that the mobile base station is capable of serving more successfully when its location is determined with the $H S$ algorithm compared to the locations determined by the ABC, PSO, and FW algorithms.

Keywords: Unmanned Aerial Vehicles, Deployment, Harmony Search Algorithm, Fireworks Algorithm

\section{Giriş}

Son y1llarda kablosuz mobil iletişimin yaygınlaşması ve kesintisiz iletişim hizmetinin bir gereksinim haline gelmesi, mobil baz istasyonu olarak kullanılmak amacıyla insansız hava araçlarının (İHA) doğru şekilde ve enerji bakımından verimli bir biçimde konumlandırılması gereksinimini ortaya koymuştur. 
Mobil baz istasyonu işlevi gören İHA'ların rastgele şekilde konumlandırılması; kapsama alanının verimsiz kullanılması, aktarım gücünün ve yol-kayıp oranının artması hususları başta olmak üzere maliyet artış1 ve performans kayıplarına yol açabilmektedir [1],[2]. Bahsedilen problemlerin çözülmesi için İHA'ların enerjilerinin verimli kullanılmasını sağlayacak şekilde konumlandırılması üzerine birçok araştırma yapılmıştır. Kamu güvenliğinin sağlanması, ortam izlemesi, lojistik destek sağlama gibi birçok konuda sıklıkla başvurulan ve zaman zaman geleneksel yöntemlerle erişilmesi güç ve hatta imkansız olabilen alanlarda ve zor şartlar altında kullanılmaya başlanılan İHA'ların optimum olarak konumlandırılması bu anlamda büyük önem taşımaktadır [3],[4].

Mobil hava baz istasyonu olarak kullanılmaya başlanılan İHA'ların kablosuz sinyallerde girişim yönetimi, aktarım gücünün minimize edilmesi ve sinyal kapsama alanının maksimuma çıkarılması başta olmak üzere birçok yeni optimizasyon problemini de beraberinde getirmiştir. Kullanımı hem hobi hem de belirli bir amaca hizmet edecek şekilde günden güne artan bu hava araçlarının sınırlı enerji kapasitesine sahip bataryalarının verimli kullanımı ve operasyon sırasındaki enerji tüketiminin incelenmesi konularına olan ilgiyi de arttırmıştır [4].

Olası acil bağlantı gereksinimi ve afet durumlarında, apartman ve gökdelen gibi yüksekliği fazla olan çok katlı binalardaki kullanıcılara, ivedi şekilde mümkün olduğunca kaliteli ve geniş kapsama alanına etki eden bağlantı hizmeti sunulması, popülerliği artan bu hava araçları ile ilgili üzerinde çalışılması gereken bir problem haline gelmiştir [5]. Bununla birlikte, İHA'ların irtifa değișimleri sırasında yeni konumunun ve cihaz dengesinin hassas olarak ayarlanmas1 nedeniyle güç tüketiminde artış meydana gelmektedir. Düşük irtifada çalışan mobil kablosuz cihazlarda bu güç tüketimi ihmal edilebilecek seviyede olsa da yüksek irtifada operasyon yürüten cihazlar için önemli seviyelere gelebilmektedir. Meydana gelen bu enerji tüketimi İHA'lara özgü bir durum olarak motorlar ve iç elektronik devrelerin güç tüketimlerinden kaynaklanmaktadır [5].

Literatürdeki çalışmalar göstermiştir ki mobil hava baz istasyonu olarak kullanılan İHA'lar için iletim gücü enerji verimliliği açısından önemli bir faktördür [6], [7]. Mobil hava baz istasyonu olarak kullanılan İHA'larda batarya ömür uzunluğu ve tek şarj ile havada kesintisiz olarak çalışma süresi büyük önem taşıdığ $\breve{1}_{1}$ için araştırmacılar iletişim sırasında harcanan gücün azaltılmasına odaklanmıştır. İletim sırasında harcanan gücünün minimizasyonu ve sinyalde meydana gelen kayıpların en aza indirgenmesi için İHA'nın optimal olarak konumlandırılması optimizasyon problemi olarak işlenmiştir.

Shakhatreh ve arkadaşları tarafindan yapılan çalışmada yüksek bir binanın tamamen kapsama alanına alınması için gerekli toplam aktarım gücünün minimize edilmesi amacıyla bir İHA'nın verimli şekilde konumlandırılması problemi formülize edilmiştir [8]. Bor-Yaliniz ve arkadaşları çalışmalarında İHA'nın üç boyutlu ortamda konumlandırılmasını karma tam sayılı doğrusal programlama olarak modellemiştir [9]. Alzenad ve arkadaşları çalışmalarında kapsama alanındaki kullanıcı sayısının maksimize edilmesi probleminde iletim gücünü bir parametre olarak ele almışlardır [10]. Mozafferi ve arkadaşları tarafından yürütülen çalışmada iletim gücünü minimize, kapsama alanını maksimize etmek için İHA'nın konumlandırılmasında daire sıkıştırma teorisinden faydalanılmıştır [11].

Kalantari ve arkadaşları, Parçacık Sürü Optimizasyonu (PSO) algoritmasını kullanarak farklı kullanıcı yoğunluklu alanlar için gerekli minimum İHA sayısının bulunması üzerine çalışmıştır [12]. Shakhatreh ve arkadaşları tarafindan yapılan bir başka çalışmada İHA konumlandırma problemi PSO kullanılarak çözülmüş [13], aynı problem daha sonradan Aslan ve Demirci tarafindan Yapay Ar1 Koloni (ABC) algoritması kullanılarak çözülmüş, yolkayıp değerlerinde iyileşme elde edilmiştir [14].

Bu çalışmada Harmoni Arama (Harmony Search, HS) ve Havai Fişek (Fireworks, FW) algoritmaları ile mobil hava baz istasyonu olarak kullanılan bir İHA'nın dış mekan-iç mekan yol-kayıp oranını minimize edecek şekilde optimal konumlandırılması işlenmiştir. Çalışmanın ilerleyen kısımlarında ise Bölüm 2'de HS algoritması açıklanmış, Bölüm 3'te FW algoritması açıklanmış, Bölüm 4'te İHA konumlandırma probleminden bahsedilmiştir.

Bölüm 5'te elde edilen sayısal sonuçlar sunularak PSO ve ABC algoritmalarıyla elde edilen sonuçlarla karşılaştırılmış, Bölüm 6 'da ise öneri ve muhtemel çalışmalara yer verilmiştir..

\section{Harmoni Arama Algoritması}

HS algoritması, 2001 yılında Geem ve arkadaşları tarafindan literatüre sunulan bir meta-sezgisel algoritmadır [15]. Kulağa hoş gelen müzik ezgilerinin bestelenmesi sirasında meydana gelen doğal süreçlerden esinlenerek geliştirilen algoritmada, çeşitli ses dalgalarının farklı frekanslarla bir araya 
gelerek harmoni oluşturan melodiler elde edilmesi süreci baz alınmıştır. Algoritmanın akış diyagramı Şekil-1'de gösterilmiştir.

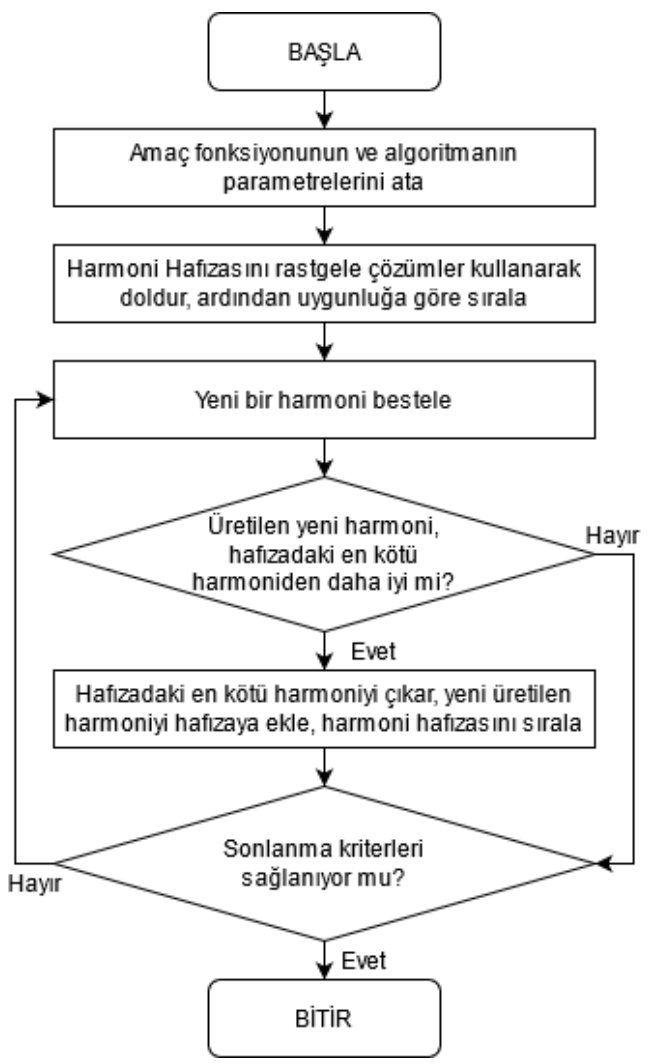

Şekil-1: HS Algoritması Akış Şeması

Harmoni hafıza boyutu, harmoni hafızasında kaç adet harmoni saklanacağını belirleyen sayısıdır. Harmoni hafizasının ilklenmesi adımında, harmoni hafiza boyutu adedince rastgele harmoni üretilerek harmoni hafizasına yerleştirilir. Harmoni hafızasındaki harmoniler, hesaplanan amaç fonksiyonu değerlerine göre en iyi çözüm en üstte olacak şekilde sıralanır.

Yeni bir harmoni bestelenmesi sırasında birkaç durum göz önünde bulundurulur. HS algoritmas1, yeni bir harmoni üretirken ilk olarak Harmoni Hafizasından Faydalanma Oranı (Harmony Memory Considering Rate, HMCR) isimli 0 ile 1 arasında değer alabilen bir parametreden faydalanır. Yeni bir harmoni üretimi sırasında rastgele olarak üretilen bir değer HMCR değerinden küçükse, yeni harmoni üretilirken harmoni hafizasindaki mevcut harmonilerden faydalanılır, büyükse yeni üretilecek harmoni ilkleme aşamasındaki gibi tamamen rastgele olarak üretilir. Çözümlerin doğruluğunu artırmak ve yerel optimum çözümlere takılma durumlarından kaçınmak için kullanılan bir diğer parametre de 0 ile 1 arasında değer alabilen Ton Ayarlama Oran1 (Pitch Adjusting Rate, PAR) parametresidir.

Rastgele olarak üretilecek bir değer PAR değerinden daha küçükse, mevcut harmoni, komşu harmoni değerlerinden faydalanılarak güncellenir. Örneğin PAR değeri 0.10 ise $\% 5$ ihtimalle üst komşu harmoninin değerinden, $\% 5$ ihtimalle de alt komşu harmoninin değerinden faydalanılarak mevcut harmoni değeri güncellenecektir.

Bestelenen yeni harmoni, harmoni hafizasındaki sonuncu, diğer bir ifade ile en kötü harmoniden daha iyiyse, hafizadaki en kötü çözüm çıkarılarak yeni bestelenen harmoni hafizaya eklenir. Ardından harmoni hafızasındaki harmoniler, amaç fonksiyon değerlerine göre tekrardan en iyi harmoni en yukarıda olacak şekilde sıralanır. Durdurma kriterlerini sağlıyorsa ya da algoritmada maksimum çevrim veya değerlendirme sayısına ulaşılmışsa algoritma sonlanır ve harmoni hafizasındaki en üstteki harmoni problemin çözümü olarak alınır. Aksi takdirde Adım 2'ye gidilerek işlemler tekrarlanır

\section{Havai Fişek (FW) Algoritması}

FW algoritmas 2010 y1lında Tan ve Zhu tarafindan literatüre sunulan bir meta-sezgisel algoritmadır [16]. Piroteknik gösteri olarak da adlandırılan havai fişek gösterileri, düşük patlayıcı gücüne sahip olan, ateşlenildiğinde havada farklı desen ve renklerde görsellik oluşturması ve patlama esnasında çıkan ses nedeni ile gösteri ve kutlama türü etkinliklerde sıklıkla uygulanmaktadır. Farklı yöntemler ve maddelerle üretilen havai fişeklerin çok sayıda çeşidi mevcut olup bazı çeşitleri dallanma şeklinde birden fazla art arda patlama ile görsel deneyimi daha yukarı taşıyabilmektedir. Havai fişeğin ateşlenerek havada patlaması ve patlamalar sonucunda oluşan kıvılcım adı verilen daha küçük parçaların da tekrardan patlayarak dallanma şeklinde geniş bir alana yayılmasından esinlenilerek oluşturulan FW algoritması iki farklı patlama durumunu benzetmeye 
çalışır. Algoritmanın akış diyagramı Şekil-2'de gösterilmiştir.

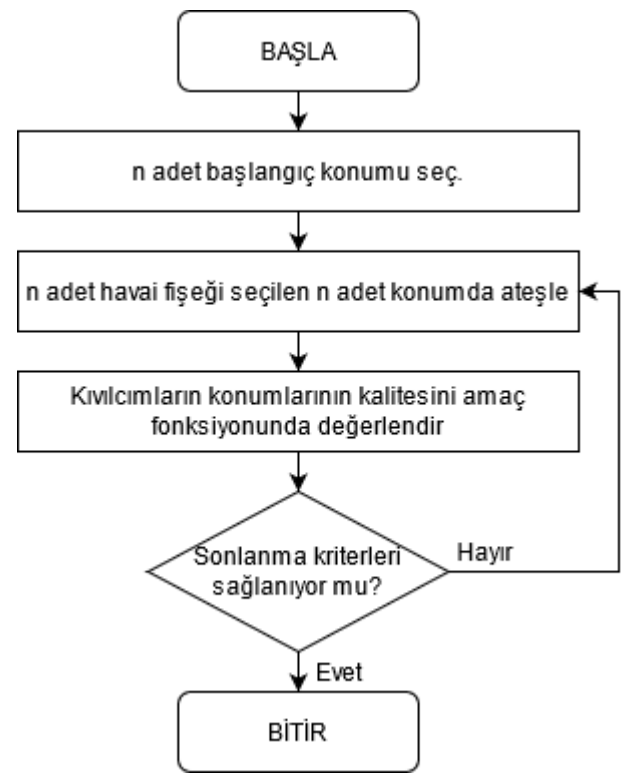

Şekil-2: FW Algoritması Akış Şeması

Algoritmada, havai fişeğin patlama süreci yerel uzaydaki belirli bir noktanın çevresinde yapılan çözüm arayışına benzetilerek kıvılcımlar yoluyla arama işlemi sürdürülür.

Algoritmanın adımları sirasında patlamalar sonucu yeni kıvılcımların meydana gelmesi sırasında gerçek hayattan uyarlanan bazı parametrelerden faydalanılır. Patlamanın kalitesi üretilen kıvılcımların yani yeni çözümlerin kalitesiyle belirlendiği için kıvılcımları doğru sayıda ve doğru mesafelerde oluşturmak önemli bir hale gelmektedir. Kıvılcımları en iyi şekilde üretmek ve en yüksek kaliteyi alabilmek adına rastgele dağılımlı ve Gauss dağılımlı olmak üzere iki farklı kıvılcım üretme stratejisine başvurulmaktadır. Üretilen kıvılcımlar doğrudan kullanılmayarak belirlenen parametreler doğrultusunda istenilen aralıklara yuvarlanılmaktadır. İki farklı yöntemle üretilen kıvılcımlar arasından en iyileri seçilerek sonraki jenerasyonda kullanılmak üzere korunmaktadır..

\section{4. İHA Konumlandırma Problemi}

Havadaki bir sinyal kaynağından bina içine sinyal iletimi sırasında meydana gelen yol-kayıp oranı ITU tarafından dış mekan-iç mekan yol kayıp kanal modeli olarak ortaya konulmuştur [17]. Bu çalışmada amaç fonksiyonu olarak faydalanılan diş mekan-iç mekan yol-kayip kanal modelinde, kablosuz sinyalin minimuma indirilen yol-kayıp oranı sayesinde, aktarım için harcanan güç miktarının da minimize edilmesi ve kısıtlı güç kaynağı kullanan İHA'nın daha uzun süre kablosuz kapsama alanı sunması amaçlanmıștır.

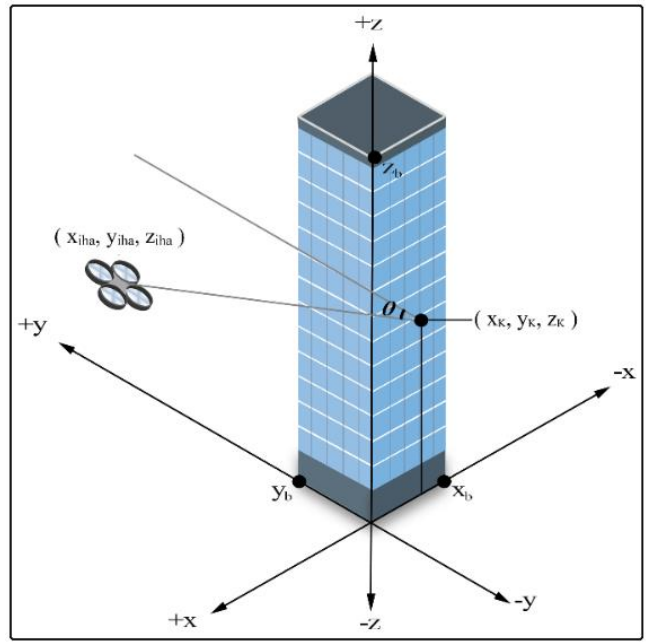

Şekil-3: İHA, kullanıcı ve bina koordinatları

Şekil-3'te kapsama alanı sunan İHA'nın konumu (xiha, yiha, ziha) ve binanın içerisindeki herhangi bir kullanıcının konumu (xK, yK, zK) olmak üzere, d3D İHA ile kullanıcı arasındaki öklid mesafesini belirtmektedir. d2D kullanıcı ile IHHA arasındaki iki boyutlu iç mekan uzaklığını, $\theta$ sinyal geliş açısını ve $\mathrm{fGHz}$ taşıyıcı frekansı belirtmek üzere toplam yolkayıp oranını minimize etmek için kullanılan ITU dış mekan-iç mekan yol-kayıp amaç fonksiyonu Eşitlik 4'te Li ile gösterilmiştir [17].

$$
\begin{aligned}
& L_{F}=\omega \log _{10}\left(d_{3 D}\right)+\omega \log _{10}\left(f_{G H z}\right)+g_{1} \\
& L_{B}=g_{2}+g_{3}(1-\cos \theta)^{2} \\
& L_{I}=g_{4} d_{2 D} \\
& L_{i}=L_{F}+L_{B}+L_{I}
\end{aligned}
$$

Eşitlik 1'de tanımlanan LF boş alan yol-kaybını, Eşitlik 2'de tanımlanan LB binaya nüfuz sırasındaki yolkaybını ve Eşitlik 3'te tanımlanan LI iç mekan yolkayıp değerini ifade etmektedir. Eşitliklerdeki $\omega$ değeri 20 olarak belirlenmiştir. ITU dış mekan-iç mekan yol kayıp kanal model değerleri referans 
alınarak g_1 değeri 32.4, duvardaki dikey yol-kayıp katsayısı (g_2) 14, duvardaki paralel yol-kayıp katsayısı (g_3) 15 ve iç mekan yol-kayıp katsayısı (g_4) 0.5 olarak belirlenmiştir [17]. $\mathrm{fGHz}$ taşıyıcı frekans değeri $2 \mathrm{GHz}$ olarak belirlenmiştir. Yüksek bir binada farklı konumlarda bulunan çok sayıda alıcıya/kullanıcıya en az yol-kayıp oranıyla kablosuz kapsama sunma probleminde, iHA ile binadaki her bir kullanıcı arasındaki yol-kayıp değerleri hesaplanarak binadaki tüm kullanıcıların toplam yol-kayıp değeri HS ve FW algoritmaları kullanılarak minimize edilmeye çalışılmıştır.

\section{Deneysel Bulgular}

HS algoritması kullanarak yüksek binada kablosuz kapsama sağlayacak şekilde İHA konumlandırma problemi çözülürken, İHA'nın olası konumları birer harmoni olarak ele alınmıştır. Harmoninin kalitesi, Eşitlik 4 kullanılarak İHA ile binadaki tüm kullanıcılar arasındaki yol-kayıp değerlerinin toplamına karşılık gelmektedir. Deneyler sırasında harmoni hafiza boyutu 100 olarak belirlenmiştir. HMCR değeri 0.75 ve 0.85 , PAR değeri 0.25 ve 0.35 , bant genişlik değeri 0.02 olarak seçilmiştir.

FW algoritmasında havai fişeklerin ve kıvılcımların havadaki konumları bina çevresinde uçan İHA'nın konumu ile eşleştirilmiştir. Deneyler sırasında algoritma parametreleri Tan ve Zhu'nun algoritmay tanıttıkları çalışmada kullanılan parametreler ile aynı olacak şekilde belirlenmiştir [16].Havai fişek sayısı 5, havai fişeklerin üretebileceği kıvılcım sayısı (si) 50 olarak belirlenmiştir. si değerinin hesaplanmasında kullanılan a ve b sabitleri sirasiyla 0.04 ve 0.8 olarak ayarlanmıştır. Maksimum patlama genliğini belirten Â değeri 40 olarak belirlenmiş, Gauss yöntemi ile üretilecek kıvılcım sayısı belirlenmiştir.

İHA'nın gezebileceği koordinatlar $\mathrm{x}$ ve y eksenleri için -1000 ile +1000 aralığ 1 ele alınmış, $z$ ekseninin değer aralığı İHA'nın zeminden daha aşağıda konumlandırılma durumlarını önlemek için 0 ile
+1000 arası olacak şekilde belirlenmiştir. Her iki algoritma ile yapılan deneylerde de İHA'nın konumu belirlenirken hem binaya hem de İHA'ya zarar gelmesinin önüne geçmek amacıyla İHA'nın binaya çarpmaması ve binanın içerisine girmemesini sağlayacak şekilde İHA için seçilen koordinatların bina koordinatlarıyla çakışmamasına dikkat edilmiş, üretilen koordinatların binanın koordinatları ile çakışıp çakışmadığının kontrolü yapılarak çakışma olması durumunda çakışmayacak şekilde yeni koordinatlar üretilerek deneye devam edilmiştir. Farklı bina boyutlarındaki yol-kayıp oranlarının izlenebilmesi için Çizelge 1'de altı farklı bina boyutu belirlenmiştir.

Çizelge-1: Test Edilen Binaların $\left|\mathbf{x}_{\mathbf{b}}\right|,\left|\mathbf{y}_{\mathbf{b}}\right|,\left|\mathbf{z}_{\mathbf{b}}\right|$ Değerleri

\begin{tabular}{|l|l|l|l|}
\hline Binalar & $\left|\mathrm{x}_{\mathrm{b}}\right|$ & $\left|\mathrm{y}_{\mathrm{b}}\right|$ & $\left|\mathrm{z}_{\mathrm{b}}\right|$ \\
\hline b1 & 20 & 50 & 200 \\
\hline b2 & 20 & 50 & 250 \\
\hline b3 & 20 & 50 & 300 \\
\hline b4 & 10 & 50 & 250 \\
\hline b5 & 30 & 50 & 250 \\
\hline b6 & 50 & 50 & 250 \\
\hline
\end{tabular}

Binalardaki kat yüksekliği 5 birim olarak belirlenmiş, rassal dağılımlı 20 kullanıcı kat tabanlarına yerleştirilmiştir. Maksimum değerlendirme sayısı 5000 olarak belirlenerek her bir bina için rastgele dağıtılmış kullanıcı konumları koşmalar sırasında sabit kalacak şekilde her bir bina için 30 bağımsız koşma gerçekleştirilmiştir. Koşmalar sırasında İHA'nın konumları ve yol-kayıp değerleri kaydedilmiş, HS algoritması için yol-kayıp değerlerinin en iyi, ortalama ve standart sapmaları Çizelge 2'de gösterilmiş, binalar için elde edilen en iyi değerler vurgulanmıştır. 
Çizelge-2: HS Algoritması İHA Konumlandırma Fonksiyonu En İyi, Standart Sapma ve Ortalama Değerleri

\begin{tabular}{|c|c|c|c|c|c|c|}
\hline \multirow{2}{*}{ Binalar } & \multicolumn{3}{|c|}{ HMCR= 0.75, PAR= 0.25 } & \multicolumn{3}{c|}{ HMCR= 0.75, PAR= 0.35 } \\
\cline { 2 - 7 } & Ortalama & Standart Sapma & En İyi & Ortalama & Standart Sapma & En İyi \\
\hline b1 & $7.00 \mathrm{E}+04$ & $6.82 \mathrm{E}+02$ & $6.92 \mathrm{E}+04$ & $7.04 \mathrm{E}+04$ & $9.28 \mathrm{E}+02$ & $6.92 \mathrm{E}+04$ \\
\hline b2 & $8.92 \mathrm{E}+04$ & $1.01 \mathrm{E}+03$ & $8.80 \mathrm{E}+04$ & $8.93 \mathrm{E}+04$ & $1.53 \mathrm{E}+03$ & $8.79 \mathrm{E}+04$ \\
\hline b3 & $1.08 \mathrm{E}+05$ & $9.46 \mathrm{E}+02$ & $1.07 \mathrm{E}+05$ & $1.09 \mathrm{E}+05$ & $1.57 \mathrm{E}+03$ & $1.07 \mathrm{E}+05$ \\
\hline b4 & $8.90 \mathrm{E}+04$ & $1.18 \mathrm{E}+03$ & $8.76 \mathrm{E}+04$ & $8.86 \mathrm{E}+04$ & $8.35 \mathrm{E}+02$ & $8.75 \mathrm{E}+04$ \\
\hline b5 & $8.94 \mathrm{E}+04$ & $6.34 \mathrm{E}+02$ & $8.84 \mathrm{E}+04$ & $8.95 \mathrm{E}+04$ & $9.16 \mathrm{E}+02$ & $8.84 \mathrm{E}+04$ \\
\hline b6 & $9.03 \mathrm{E}+04$ & $8.29 \mathrm{E}+02$ & $8.93 \mathrm{E}+04$ & $9.03 \mathrm{E}+04$ & $7.21 \mathrm{E}+02$ & $8.93 \mathrm{E}+04$ \\
\hline \multirow{2}{*}{ Binalaryyyyyy} & \multicolumn{2}{|c|}{ HMCR= 0.85, PAR= 0.25 } & \multicolumn{2}{c|}{ HMCR= 0.85, PAR= 0.35 } \\
\cline { 2 - 8 } b1 & $7.04 \mathrm{E}+04$ & $1.03 \mathrm{E}+03$ & $6.92 \mathrm{E}+04$ & $7.06 \mathrm{E}+04$ & $8.65 \mathrm{E}+02$ & $6.92 \mathrm{E}+04$ \\
\hline b2 & $8.90 \mathrm{E}+04$ & $7.52 \mathrm{E}+02$ & $8.79 \mathrm{E}+04$ & $8.93 \mathrm{E}+04$ & $1.03 \mathrm{E}+03$ & $8.79 \mathrm{E}+04$ \\
\hline b3 & $1.09 \mathrm{E}+05$ & $1.28 \mathrm{E}+03$ & $1.07 \mathrm{E}+05$ & $1.09 \mathrm{E}+05$ & $1.53 \mathrm{E}+03$ & $1.07 \mathrm{E}+05$ \\
\hline b4 & $8.87 \mathrm{E}+04$ & $9.25 \mathrm{E}+02$ & $8.75 \mathrm{E}+04$ & $8.90 \mathrm{E}+04$ & $1.50 \mathrm{E}+03$ & $8.75 \mathrm{E}+04$ \\
\hline b5 & $8.97 \mathrm{E}+04$ & $8.84 \mathrm{E}+02$ & $8.84 \mathrm{E}+04$ & $9.00 \mathrm{E}+04$ & $1.82 \mathrm{E}+03$ & $8.83 \mathrm{E}+04$ \\
\hline b6 & $9.06 \mathrm{E}+04$ & $1.09 \mathrm{E}+03$ & $8.93 \mathrm{E}+04$ & $9.08 \mathrm{E}+04$ & $1.31 \mathrm{E}+03$ & $8.93 \mathrm{E}+04$ \\
\hline
\end{tabular}

Çizelge-3: FW Algoritması IHA Konumlandırma Fonksiyonu En İyi, Standart Sapma ve Ortalama Değerleri

\begin{tabular}{|c|c|c|c|}
\hline \multirow{2}{*}{ Binalar } & \multicolumn{3}{|c|}{ Havai Fişek Adedi= 5, a= 0.04, b= 0.8 } \\
\cline { 2 - 4 } & Ortalama & Standart Sapma & En İyi \\
\hline b1 & $8.87 \mathrm{E}+04$ & $1.04 \mathrm{E}+04$ & $7.05 \mathrm{E}+04$ \\
\hline b2 & $1.20 \mathrm{E}+05$ & $1.47 \mathrm{E}+04$ & $9.83 \mathrm{E}+04$ \\
\hline b3 & $1.41 \mathrm{E}+05$ & $2.32 \mathrm{E}+04$ & $1.12 \mathrm{E}+05$ \\
\hline b4 & $1.15 \mathrm{E}+05$ & $2.51 \mathrm{E}+04$ & $8.91 \mathrm{E}+04$ \\
\hline b6 & $1.12 \mathrm{E}+05$ & $1.69 \mathrm{E}+04$ & $8.91 \mathrm{E}+04$ \\
\hline & $1.15 \mathrm{E}+05$ & $2.18 \mathrm{E}+04$ & $9.25 \mathrm{E}+04$ \\
\hline
\end{tabular}

Harmoni hafiza boyutu, başlangıçta rastgele olarak elde edilen çözüm çeşitliliğini sağlamak üzere 100 olarak belirlenmiştir. Harmoni hafiza boyutu, algoritmanın başlangıç aşamasındaki hafizanın doldurulması sürecinde tek seferliğine hafiza boyutu sayısınca değerlendirme yapılmasına neden olarak tek seferliğine değerlendirme sayısını artırmaktadır. Sonrasında harmoni hafizasındaki eleman sayısının yüksek olması, sıralama haricinde işlem yükü getirmemekte ve hafizada kullanılan alan da harmoni hafiza boyutuyla sinırlı kalmaktadır. HMCR parametresi koşturma deneyimlerine dayanılarak bu problem için 0.75 ve 0.85 olarak belirlenmiştir. HMCR parametresinin çok küçük seçilmesi halinde harmoni hafizasındaki kaliteli çözümlerden yararlanma ihtimali düşerek algoritmanın daha rassal ilerlemesine neden olmakta, çok büyük seçilmesi de harmoni hafizasındaki o zamana kadar bulunmuş kaliteli çözümlerden yoğun faydalanılmasına ve algoritmanın küresel araştırma özelliğinin azalmasına neden olmaktadır. PAR değeri ise 0.25 ve 0.35 olarak belirlenmiştir. İHA konumlandırma probleminin FW algoritması ile çözümü için HS algoritması ile yapılan çözümde olduğu gibi Çizelge 1'de belirtilen altı farklı bina boyutu ile deneyler gerçekleştirilmiştir. Her bir bina için binanın içerisinde rastgele olarak belirlenmiş kullanıcıların konumları koşmalar sırasında sabit TÜRKIYE BILIŞIM VAKFI BILGISAYAR BILIMLERI ve MÜHENDISLIĞi DERGISi (2021 Cilt:14 - Sayı:1) - 73 
bırakılmıştır ve yine her bir bina için 30 bağımsız koşma gerçekleştirilmiştir. Gerçekleştirilen koşmalar sırasında İHA'nın aday konumları ve yol-kayıp değerleri HS algoritmasında olduğu gibi kaydedilmiş, FW algoritması için yol-kayıp değerlerinin en iyi, ortalama ve standart sapmaları Çizelge 3'te gösterilmiştir.

Her iki algoritma kullanılarak yapılan koşmalardan elde edilen sonuçlar, problemin benzer problemlerin optimizasyonunda siklıkla başvurulan ve bu problem için de daha önceden literatürde çalışmaları yer alan diğer meta-sezgisel algoritmalar olan PSO ve ABC kullanılarak elde edilen sonuçları ile karşılaştırılmıştır. Adil şartlar altında 30 bağımsız koşmanın sonuçlarını içeren Çizelge 4'te PSO, ABC ve bu çalışmadaki HS ve FW algoritmaları ile elde edilen sonuçlar ve sonuçların elde edildiği İHA koordinatları verilmiştir. Her bir bina için çizelgedeki algoritmalar arasında elde edilen en iyi sonuçlar vurgulanmıştır. Çizelgedeki sonuçlardan da görülebileceği üzere, HS algoritması İHA'nın konumlandırılmasında $A B C$ ve PSO algoritmalarından ve bu çalışma kapsamında değerlendirilen diğer bir meta-sezgisel algoritma olan FW algoritmasından daha iyi sonuçlar elde etmiştir. Çizelgelerdeki koordinat değerlerinin incelenmesi durumunda, özellikle $\mathrm{x}$ koordinatı için bulunan değerlerden de anlaşılacağı üzere $A B C$ ve $P S O$ algoritmalarının, binanın bir yüzeyinde kaldığını, HS ve $\mathrm{FW}$ algoritmalarının ise sirasiyla rastgele harmoni üretme stratejisi ve iki farklı yöntemle uzayda yeni kıvılcımların konumlandırılması stratejileri sayesinde binanın farklı cephesine geçebildiği, bu cephede diğer cepheye göre daha iyi sonuçlar elde edebildiği anlaşılmaktadır. $\mathrm{Bu}$ sayede $\mathrm{HS}$ ve $\mathrm{FW}$ algoritmalarının bu problem için yerel uygun değer çözümlerin etkisinden kurtulma konusunda daha başarılı oldukları söylenebilir. b4, b5 ve b6 binaları için dört farklı algoritma ile elde edilen sonuçların karşılaştırılması Şekil-4'te gösterilmiştir.

Bina taban boyutları 20 ve 50 olmak üzere aynı olan b1, b2 ve b3 binaları için dört farklı algoritma ile elde edilen sonuçların karşıllaştırılması Şekil-5'te görselleştirilmiştir.

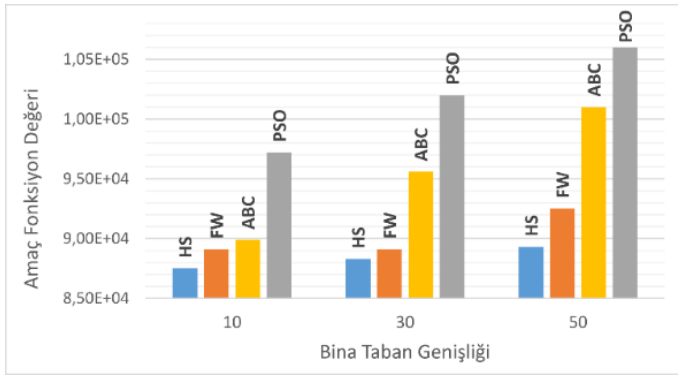

Şekil-4: b4, b5 ve b6 binaları için yol-kayıp değerlerinin karşılaştırması

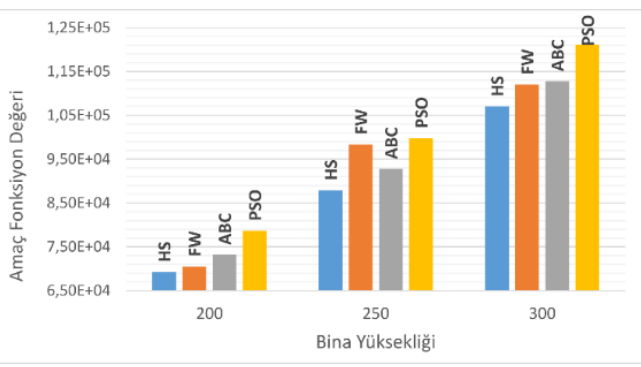

Şekil-5: b1, b2 ve b3 binaları için yol-kayıp değerlerinin karşılaştırması

HS algoritması HMCR faktörü sayesinde diğer çözümlerden tamamen bağımsız şekilde yeni çözümler üretebilmekte, PAR faktörü sayesinde ise daha önceki çözümlerden faydalanarak önceki çözümleri harmanlayan yeni çözümler üretilmesini sağlamaktadır. Yeni harmoni üretilirken kullanılan HMCR ve PAR parametreleri ilgilenilen problemde İHA'nın binanın tek bir cephesinde gezmesinin önüne geçerek daha iyi sonuçlar elde etmesini sağlamıştır.

HS algoritmasında başlangıçta rastgele üretilen harmoni sayısını belirleyen harmoni hafiza boyutu ile yeni harmoniler üretirken faydalanılan $H M C R$ ve $P A R$ değerleri doğru çözüme ulaşma hızına oldukça etki etmektedir. Harmoni hafiza boyutunun çok yüksek seçilmesi fazla hafiza kullanımına, $H M C R$ ve $P A R$ değerlerinin çok düşük ve çok yüksek belirlenmesi algoritmanın fazla rastgele olmasına veya eski çözümlere fazla bağlı kalmasına neden olmaktadır. Bu nedenle bu üç parametre çözüme ulaşma hızında kilit rolü oynamaktadır 
Çizelge 4: HS, FW, PSO ve ABC Algoritmalarının Sonuç Karşılaştırması

\begin{tabular}{|c|c|c|c|c|}
\hline \multirow{2}{*}{ Binalar } & \multicolumn{2}{|r|}{ HS } & \multicolumn{2}{|r|}{ FW } \\
\hline & En İyi & $\left(x_{e}, y_{e}, z_{e}\right)$ & En İyi & $\left(x_{e}, y_{e}, z_{e}\right)$ \\
\hline b1 & $6.92 \mathrm{E}+04$ & $(-2.8195,54.0172,96.0613)$ & $7.05 \mathrm{E}+04$ & $(0.8644,13.5860,135.4962)$ \\
\hline b2 & $8.79 \mathrm{E}+04$ & $(5.3252,28.6593,122.4105)$ & $9.83 \mathrm{E}+04$ & $(8.5591,-8.4873,29.0978)$ \\
\hline b3 & $1.07 \mathrm{E}+05$ & $(0.6614,21.5299,134.4256)$ & $1.12 \mathrm{E}+05$ & $(0.0342,0.7695,26.3276)$ \\
\hline b4 & $8.75 \mathrm{E}+04$ & $(0.9157,30.6662,123.2396)$ & $8.91 \mathrm{E}+04$ & $(2.0718,36.6692,100.6307)$ \\
\hline b5 & $8.83 \mathrm{E}+04$ & $(1.4475,38.7260,118.9891)$ & $8.91 \mathrm{E}+04$ & $(0.4970,20.1543,154.6200)$ \\
\hline b6 & $8.93 \mathrm{E}+04$ & $\begin{array}{c}(-0.1247,39.5617,118.1806 \\
)\end{array}$ & $9.25 \mathrm{E}+04$ & $(2.4139,38.5846,48.9115)$ \\
\hline \multirow{2}{*}{ Binalar } & \multicolumn{2}{|r|}{ PSO [13] } & \multicolumn{2}{|r|}{ ABC [14] } \\
\hline & En İyi & $\left(x_{e}, y_{e}, z_{e}\right)$ & En İyi & $\left(x_{e}, y_{e}, z_{e}\right)$ \\
\hline b1 & $7.8645 \mathrm{e}+04$ & $\begin{array}{c}(-21.7995,37.3891, \\
111.7901)\end{array}$ & $7.3185 \mathrm{e}+04$ & $(-20.0028,26.5781,91.2785)$ \\
\hline b2 & $9.9725 \mathrm{e}+04$ & $\begin{array}{c}(-32.9212,28.7125, \\
124.0291)\end{array}$ & $9.2753 \mathrm{e}+04$ & $\begin{array}{c}(-20.0086,25.3626, \\
119.6259)\end{array}$ \\
\hline b3 & $1.2117 \mathrm{e}+05$ & $\begin{array}{c}(-46.5898,31.5061 \\
143.8588)\end{array}$ & $1.1276 \mathrm{e}+05$ & $\begin{array}{c}(-20.0463,28.5552 \\
144.9335)\end{array}$ \\
\hline b4 & $9.7252 \mathrm{e}+04$ & $\begin{array}{c}(-32.1042,21.0174 \\
129.2663)\end{array}$ & $8.9948 \mathrm{e}+04$ & $(0.0117,27.5426,124.8586)$ \\
\hline b5 & $1.0211 \mathrm{e}+05$ & $(-25.5294,4.9387,138.7650)$ & $9.5692 \mathrm{e}+04$ & $\begin{array}{c}(-30.0056,28.9812 \\
114.7224)\end{array}$ \\
\hline b6 & $1.0696 \mathrm{e}+05$ & $\begin{array}{c}(-14.5488,17.3082, \\
131.8940)\end{array}$ & $1.0135 \mathrm{e}+05$ & $\begin{array}{c}(-26.5533,50.0502 \\
120.7505)\end{array}$ \\
\hline
\end{tabular}

\section{Sonuç}

$\mathrm{Bu}$ çalışmada $\mathrm{HS}$ ve FW algoritmalarının mobil hava baz istasyonu olarak kullanılan bir İHA'nın farklı boyutlardaki binalarda rastgele dağılmıș kullanıcılara en düșük yol-kayıp oranıyla bağlantı sunabilmesi için optimum konumlandırılması problemi üzerindeki performansları incelenmiştir. HS algoritması ile elde edilen sonuçlar, aynı problemin $\mathrm{ABC}$, $\mathrm{PSO}$ ve $\mathrm{FW}$ algoritmaları kullanılarak elde edilen çözümlerinden daha kaliteli olduğunu göstermiştir. Gelecekte, İHA konumlandırma problemi çoklu İHA'lar ve farklı yolkayıp hesaplama modelleri kullanılarak çözülebilir. Ayrica, yeni meta-sezgisel algoritmaların seri ve paralel uygulamalarının İHA konumlandırma probleminin çözümündeki performansı tek ve çoklu binalar içerisindeki kullanıcılar hesaba katılarak incelenebilir.

\section{Bilgilendirme}

$\mathrm{Bu}$ çalışma 5. Uluslararası Bilgisayar Bilimleri ve Mühendisliği Konferansında (UBMK 2020) sunulan [18] numaralı çalışmanın geniş̧letilmiş halidir.

\section{Kaynakça}

[1] Al-Hourani, A. Kandeepan, S. ve Jamalipour, A., Modeling air-toground path loss for low altitude platforms in urban environments, in IEEE Global Communications Conference, pp. 28982904, 2014.

[2] Bupe P., Haddad R., ve Rios-Gutierre, F., Relief and emergency communication network based on an autonomous decentralized uav clustering network, in IEEE SoutheastCon, pp. 1-8, 2015.

[3] Shakhatreh, H. Khreishah, A. Chakareski, J. Salameh, H. B. ve Khalil, I., On the continuous coverage problem for a swarm of UAVs, in IEEE 37th Sarnoff Symposium, pp. 130-135, 2016.

[4] Motlagh, N. H. Taleb, T. ve Arouk, O. Lowaltitude unmanned aerial vehicles-based internet of things services: comprehensive survey and future perspectives, IEEE Internet of Things Journal, vol. 3, no. 6, pp. 899-922, 2016.

[5] Gupta, L. Jain, R. ve Vaszkun, G. Survey of important issues in UAV communication 
networks, IEEE Comunication Surveys Tutorials, vol. 18, no. 2, pp. 1123-1152, 2016.

[6] Mozaffari, M. Saad, W. Bennis, M. ve Debbah, M., Drone small cells in the clouds: desing, deployment and performance analysis, in IEEE Global Communications Conference, pp. 1-6, 2015.

[7] Mozaffari, M. Saad, W. Bennis, M. ve Debbah, M., Unmanned aerial vehicle with underlaid device-to-device communications: performance and tradeoffs, IEEE Transactions on Wireless Communications, vol. 15 , no. 6, pp. 3949-3963, 2016.

[8] Shakhatreh, H., Khreishah, A. ve Ji, B., Providing wireless converage to high-rise buildings using uavs, in IEEE International Conference on Communications, pp. 1-6, 2017.

[9] Bor-Yaliniz, R. I. El-keyfi, A. ve Yanikomeroglu, H., Efficient $3 D$ placement of an aerial base station in next generation cellular networks, in IEEE International Conference on Communications, pp. 1-5, 2016.

[10] Alzenad, M. El-keyfi, A. Lagum, F. ve Yanikomeroglu, H. 3-D placement of an unmanned aerial vehicle base station (UAV-BS) for energy-efficient maximal coverage, IEEE Wireless Communications Letters, vol. 6, no. 4, pp. 434-437, 2016.

[11] Mozaffari, M. Saad, W. Bennis, M. ve Debbah, M., Efficient deployment of multiple- unmanned aerial vehicles for optimizal wireless coverage, IEEE Communication Letters, vol. 20, no. 8, pp. 1647-1650, 2016.

[12] Kalantari, E. Yanikomeroglu, H. ve Yongacoglu, A., On the number and $3 d$ placement of drone base stations in wireless cellular networks, in IEEE Vehicular Technology Conference, pp. 18-21, 2016.

[13] Shakhatreh, H. Khreishah, A. Alsarhan, A. Khalil, I. Sawalmeh, A. ve N. Othman, S., Efficient $3 d$ placement of a uav using particle swarm optimization, in IEEE 8th International Conference on Information and Communication Systems, pp. 258-263, 2017.

[14] Aslan, S. ve Demirci, S. Solving UAV Localization Problem with Artificial Bee Colony (ABC) Algorithm, 2019 4th International Conference on Computer Science and Engineering (UBMK), Samsun, Turkey, 2019, pp. 735-738. doi: 10.1109/UBMK.2019.8907034 TÜRKIYE BiLIŞiM VAKFI BILGISAYAR BILIMLERI ve MÜHENDISLiĞi DERGISi (2021 Cilt:14 - Sayı:1) - 76
[15] Geem, Z. W. Kim, J. H. ve Loganathan G. V., A new heuristic optimization algorithm: Harmony Search., Simulation, 76(2), 60-68, 2001

[16] Tan, Y., Zhu, Y. Fireworks algorithm for optimization. International conference in swarm intelligence (pp. 355-364). Springer, Berlin, Heidelberg, June 2010.

[17] Series, M. Guidelines for evaluation of radio interface technologies for imt-advanced, Report ITU, no. 2135-1, 2009.

[18] İleri, S. C. Aslan S. ve Demirci, S., Finding Optimum Location for a Mobile Aerial Base Station with Harmony Search Algorithm, 2020 5th International Conference on Computer Science and Engineering (UBMK), Diyarbakir, Turkey, 2020, pp. 224-227, doi: 10.1109/UBMK50275.2020.9219538 